\title{
Review \\ Hybrid Organic-Inorganic Materials on Metallic Surfaces: Fabrication and Electrochemical Performance
}

\author{
Nisa Nashrah, Rosy Amalia Kurnia Putri, Early Zahwa Alharissa, Wail Al Zoubi * and Young Gun Ko * \\ Materials Electrochemistry Group, School of Materials Science and Engineering, Yeungnam University, \\ Gyeongsan 38541, Korea; nisanashrah@ynu.ac.kr (N.N.); rosyamalia@ynu.ac.kr (R.A.K.P.); \\ earlyzahwa@yu.ac.kr (E.Z.A.) \\ * Correspondence: wailalzoubi@ynu.ac.kr (W.A.Z.); younggun@ynu.ac.kr (Y. G.K.)
}

check for

updates

Citation: Nashrah, N.; Putri, R.A.K.; Alharissa, E.Z.; Al Zoubi, W.; Ko, Y.G. Hybrid Organic-Inorganic Materials on Metallic Surfaces: Fabrication and Electrochemical Performance. Metals 2021, 11, 1043. https://doi.org/ $10.3390 /$ met11071043

Academic Editor: Changdong Gu

Received: 28 April 2021

Accepted: 28 June 2021

Published: 29 June 2021

Publisher's Note: MDPI stays neutral with regard to jurisdictional claims in published maps and institutional affiliations.

Copyright: (C) 2021 by the authors Licensee MDPI, Basel, Switzerland. This article is an open access article distributed under the terms and conditions of the Creative Commons Attribution (CC BY) license (https:/ / creativecommons.org/licenses/by/ $4.0 /)$.

\begin{abstract}
In recent years, hybrid organic-inorganic (HOI) materials have attracted massive attention as they combine the unique properties of organic and inorganic compounds. In this review, we focus on the formation of HOI materials and their electrochemical performance that can be controlled by microstructural design depending upon their chemical composition. This overview outlines the recent strategies of preparing HOI materials on metallic surface via wet-electrochemical systems, such as plasma electrolysis (PE) and dip chemical coating (DCC). The corresponding electrochemical behavior for short and long term exposures is also summarized.
\end{abstract}

Keywords: hybrid organic-inorganic; light metal; plasma electrolysis; dip chemical coating; selfassembly; electrochemical performance

\section{Introduction}

The increasing demand for light metallic materials for use in cutting-edge applications of corrosion protection, catalytic activity, and bio-related performance has stimulated comprehensive studies among researchers around the world [1]. To improve the performance of light metals ( $\mathrm{Mg}, \mathrm{Al}, \mathrm{Ti}$, etc.) and their alloys, wet surface treatments, including chemical conversion, anodizing, and plasma electrolysis (PE) have been employed to deposit a protective layer on the metallic surface [1-5]. Among these strategies, PE (also denoted as micro-arc oxidation) is able to reform the surface of $\mathrm{Mg}, \mathrm{Al}$, Ti under high electrical polarization by utilizing myriads of plasma discharges accompanying the formation of an inorganic layer (IL) [1,4]. This approach has several advantages compared with other surface treatments, including single-step processing, ease of control, and the capability of generating a crystalline IL structure with outstanding adhesion to the metal substrate $[6,7]$. Although the adhesion and protection of ILs on metal surfaces are excellent, the surface morphology remains vulnerable to corrosion attack due to the presence of micro-defects resulting from plasma discharge activities [8].

Organic compounds have been used to seal the defects since porous IL provide them favorable sites to interact with functional groups in organic molecules for fabricating hybrid organic-inorganic (HOI) materials by additional chemical treatments. These strategies comprise electrophoretic deposition, sol-gel, dip chemical coating (DCC), etc. For example, Malayoglu, et al. [9] combined PE with DCC to impart an organic layer (OL) on the defective surface of IL. To this end, they immersed IL grown on AM50 alloy into a solution containing tetraethylorthosilicate (TEOS) and methyltriethoxysilane (MTES) which caused a decrease in the IL defective surface, leading to an outstanding electrochemical performance. Using a similar method, other sealing agents, such as dimethyl-5hydroyisophthalate (DMIP) [10], 8-hydroxyquinoline (also known as 1-azanaphthalene-8$\mathrm{ol}$ ) [11,12], and 4-[4-(phyenylazo)phenylazo]-o-cresol (PPC) [13] have been also applied as corrosion inhibitors combined with the inorganic porous materials in a bid to improve their structural integrity, thereby enhancing the corrosion resistance, especially during 
long-term exposure [14]. Therefore, the combination of organic and inorganic components may suggest the facile formation of HOI materials with different architecture manipulating their electrochemical performance.

The present work is a timely review on the bottom-up fabrication and polarization behavior of HOI materials formed on a metallic surface. This review begins with a first part describing the self-assembly of organic molecules and understanding its formation mechanism on the defective surface of IL made by PE. Thereafter, the second part, the improvement in corrosion protection of HOI materials consisting IL-OL system on metallic surface will be briefly outlined. Lastly, we also provide a comparative summary on the electrochemical properties (e.g., $i_{\text {corr, }} E_{\text {corr, }}$ corrosion rate) of various HOI materials fabricated via PE-DCC reported earlier.

\section{On the Strategy of Preparing HOI Materials: Self-Assembly and Formation Mechanism}

A number of bottom-up strategies for designing HOI materials on the surface of light metals, in particular $\mathrm{Mg}$ and $\mathrm{Al}$ alloys, have been continuously developed since either inorganic or organic layers alone are unlikely to provide sufficient stability in harsh environments [15]. A creative design combining together inorganic and organic layers on the metallic substrate has stimulated the advent of high-performance materials to meet the expectations in which the electrochemical aspect would be satisfied. By means of PE, where the metallic substrate is reformed in a liquid electrolyte through plasma dischargeassisted electrochemical reactions under high electrical polarization, a thick IL grown on the substrate with strong adhesion to the substrate would be attained [16,17]. However, during PE, the high energy discharges are not only constructive for the growth of the IL responsible for its thickness, but also destructive in nature leaving micro-defects on the IL surface which might be detrimental to its structural integrity unless defect remediation were performed [18]. Introducing these defects as sites for the preferential adsorption of organic molecules represents a new hybrid concept to fabricate HOI materials on the metallic surface, aiming to improve their structural stability. This key concept relies on the condition where the hierarchical porous structure of IL act as a reservoir that allows local anchoring of organic moieties through donor-acceptor interactions depending upon the surface charge of the metal and electronic properties of the organic source $[1,18]$. Thus, unpaired electrons, polar functional groups, aromatic rings, and several heteroatoms (i.e, $\mathrm{N}, \mathrm{P}, \mathrm{S}$ ) would preferably donate electrons to the unfilled d-or p-orbitals of the metal in the IL. Such electrostatic interactions would be the driving force to allow direct self-assembly of the organic moieties to finally form 2D or 3D spatial hybrid architectures, depending upon their nucleation and anisotropic growth that are affected by the concentration of the organic compound and the processing time $[19,20]$.

Up to now, several works have been devoted to attempts to fabricate HOI materials on porous IL grown on a metallic surface. A two-step process combining PE and DCC allows self-assembly of organic compounds on the porous IL. For instance, subsequent to PE, DCC treatment of PE-coated AZ31 Mg alloy was successfully carried out to grow OL via self-assembly of diethyl-5-hydroxyisophthalate (DEIP) [20]. In this work, IL grown on AZ31 Mg alloy was immersed in a 2 M ethanolic DEIP solution for 2 days. Generally, in ethanolic solutions, the organic molecules exist either as neutral molecules (phenol) or in the form of protonated organic molecules (phenolate ion or phenoxide ion). The neutral organic compound might be adsorbed on the surface of the inorganic coating via chemisorption mechanism, involving the displacement of water or ethanol molecules from the surface coating or metal (through the pores) and the sharing of electrons between the hetero-atoms and metals as shown in chemical reaction below:

$$
\operatorname{Organic}_{(\text {sol })}+x \mathrm{H}_{2} \mathrm{O} / \mathrm{C}_{2} \mathrm{H}_{5} \mathrm{OH}_{(a d s)} \stackrel{x}{\leftrightarrow} \operatorname{Organic}_{(\text {ads })}+x \mathrm{H}_{2} \mathrm{O} / \mathrm{C}_{2} \mathrm{H}_{5} \mathrm{OH}_{(\text {sol })}
$$

The adsorption of DEIP on the coating surface occurs by several ways: (a) electrostatic interaction between the charged centers of the molecules and the charged coating, (b) 
donor-acceptor interaction between unshared electron pairs in the molecule and the vacant d-orbital of the metal surface atoms, (c) donor-acceptor interaction between the $\pi$-electrons of the aromatic ring and the multiple bonds and vacant d-orbitals of the metal surface atoms, and (d) donor-acceptor interaction between the d-electrons of surface metal-atoms, and the empty antibonding molecular orbital of DEIP (retro-donation) [20]. Tailoring the structure of HOI layer is critical as it is responsible for the stability against corrosion, especially those with three-dimensional architectures [1]. Al Zoubi et al. [13] reported the formation of 3D flower-like structures on the top of a porous $\mathrm{MgAl}_{2} \mathrm{O}_{4}$ layer via self-assembly of PPC clusters in ethanolic solution during DCC for 1 day (the process is illustrated in Figure 1a). The different concentration of PPC was found to significantly influence the anisotropic growth of the OL, resulting in different flower structures. At the initial stage, PPC molecules having phenol, azo, and aromatic ring functional groups form charge transfer complexes with the inorganic surface via non-covalent interactions including $\pi-\pi$ interaction, van der Waals forces, and hydrogen bonding to form primary crystals at microdefects on the surface of the PE layer. This causes separate petals to emerge and finally anisotropic growth results in the whole formation of a 3D flower-like structure depending on the concentration of PPC as shown in Figure $1 \mathrm{c}-\mathrm{d}$ for $1 \mathrm{M}$ and $2 \mathrm{M}$ PPC, respectively [13]. The organic chain was observed to be $0.25 \mathrm{~nm}$ approximately by TEM (Figure 1e-f) representing the lattice vector of the PPC unit cell. The upright molecular geometry pointed out by blue arrow was anticipated from $\pi$ stacking interaction between aromatic backbones of the adjacent PPC molecules which form intramolecular hydrogen bonds, stabilizing the flower structure.
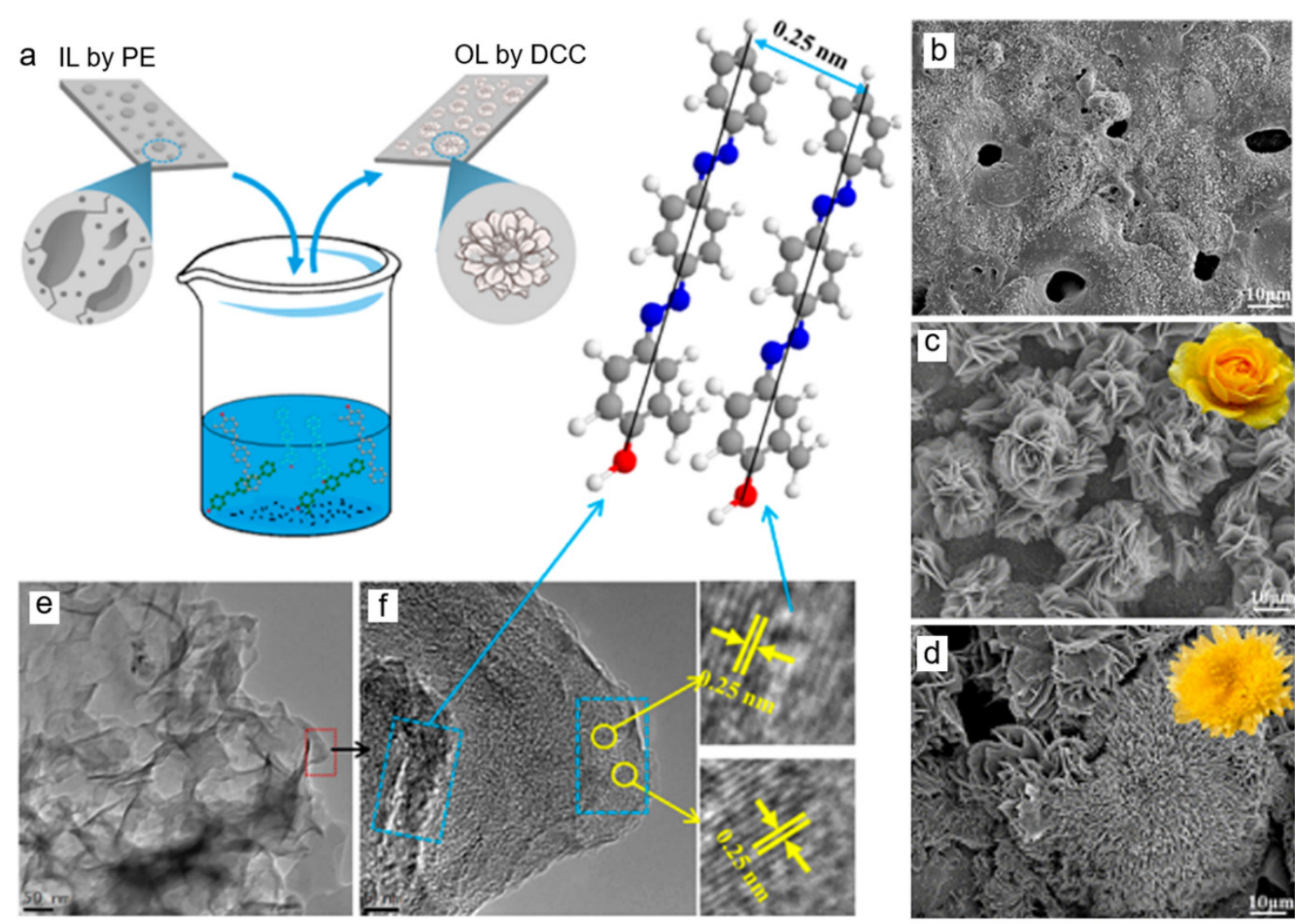

Figure 1. Fabrication of HOI material on AZ31 Mg surface showing a schematic illustration (a) describing IL (b) subjected to DCC containing PPC molecules with different concentration of $1 \mathrm{M}$ (c) and $2 \mathrm{M}$ (d). A representative TEM (e) and HR-TEM (f) images of flower petals. Reproduced with permission from [13]. Copyright (c) 2018 American Chemical Society. 
Using a similar approach, the self-assembly of DMIP molecules on the porous $\mathrm{MgAl}_{2} \mathrm{O}_{4}$ layer produced conformal OL with 3D basket-weave structure [10]. Figure 2a shows the porous IL obtained by PE prior to the immersion in ethanolic solution containing DMIP. After $13 \mathrm{~h}$ immersion, the non-specific $\mathrm{H}$ bonds between DMIP molecules hold their single molecules together and nucleate to form a weave-like structure on the microdefect site as shown in Figure 2b. The interactions between vacant orbitals in the $\mathrm{MgAl}_{2} \mathrm{O}_{4}$ phase of $\mathrm{IL}$ and the electron donor, such as $-\mathrm{OH}$ and $-\mathrm{CO}$ in DMIP would facilitate the electron transfer from OL to IL. These interactions involve non covalent $\pi-\pi$ electrons stacking between aromatic cores as well as the interaction between polar functional groups, in which further immersion up to $30 \mathrm{~h}$ allows the arrangement of $\mathrm{H}$ bonds whose distance between organic chains was $\sim 0.79 \mathrm{~nm}$ to finally form 3D-basket weave structure as shown in Figure 2c [10].
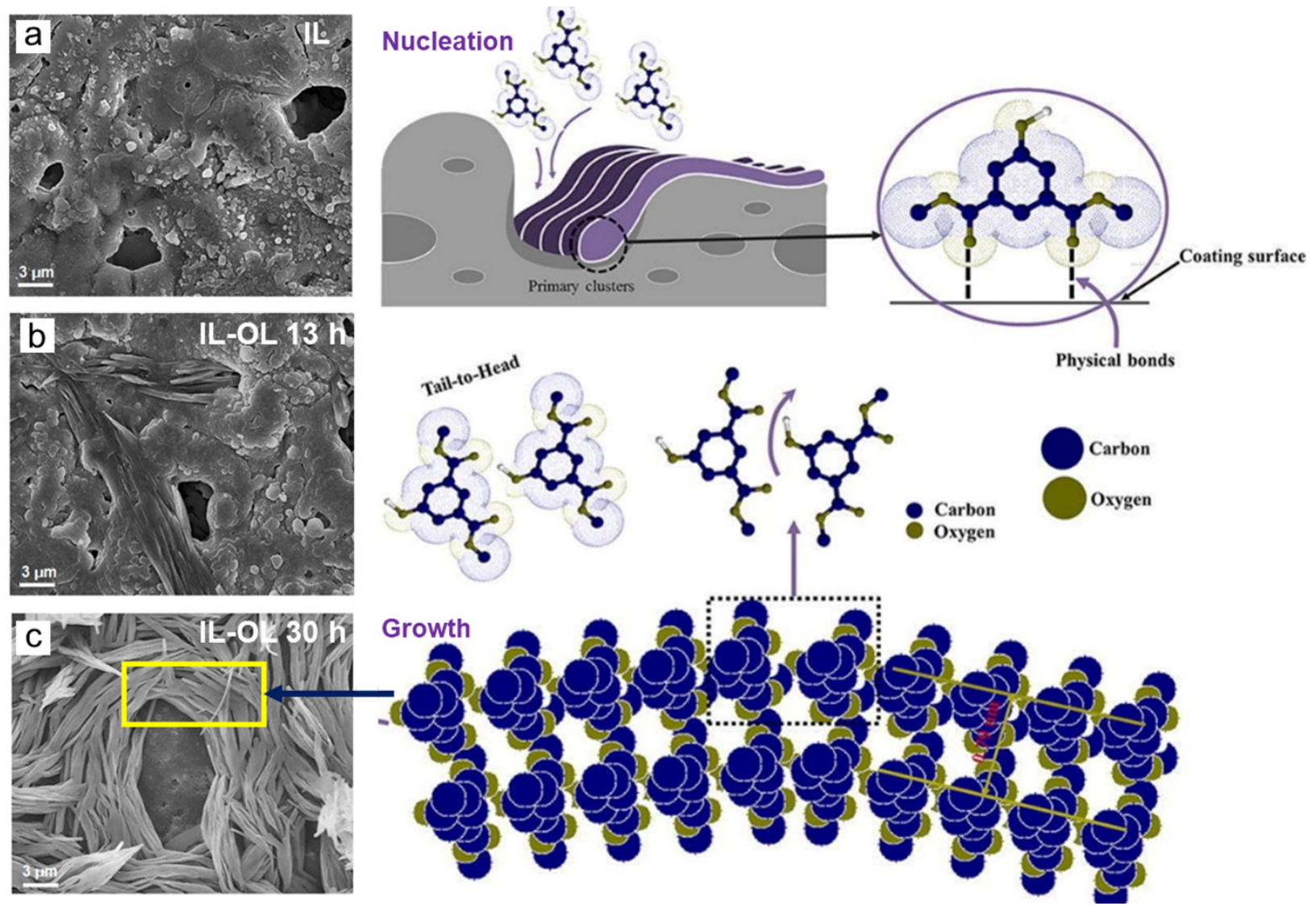

Figure 2. Surface morphologies of IL after PE (a) and IL-OL with 3D basket-weave structure after dip chemical coating in

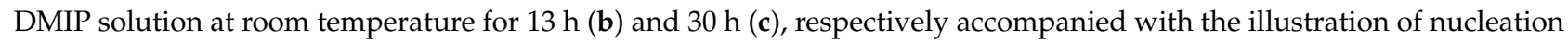
and growth of the organic cluster. Redrawn with permission from [10]. Copyright @ 2019 Elsevier.

In addition to the organic compounds discussed in previous works, it is reported that DCC performed in specific solution containing organic inhibitors turned out to be desirable for blocking micropores in inorganic coatings. Thus, several works shed a light on choosing a corrosion inhibitor as the organic source, including thiourea and hydroquinone. The corrosion protection would be expected synergistically not only from its microstructure providing compact sealing layer but also to its composition containing chemically-stable corrosion inhibitor. For instance, thiourea was grown conformably on the defective IL of AZ31 Mg substrate via one step DCC process subsequent to PE [19]. The substrate was immersed in an aqueous solution containing $3 \mathrm{M}$ thiourea at room temperature for $20 \mathrm{~h}$. Thiourea interacts with the pores in the surface of IL via electrostatic interaction between polar group containing one $\mathrm{S}$ atom and two $\mathrm{N}$ atoms in the organic 
molecules and porous surface in IL. The formation mechanism of OL on the porous IL and interaction between thiourea and the IL surface/solution interface can involve: (i) charge-transfer-type interaction between the unshared $\pi$ electron pairs $(\mathrm{S}$ and $\mathrm{N}$ ) and the vacant orbitals of $\mathrm{Mg}$ atoms or metal oxides (chemisorption at anodic sites); (ii) electrostatic interactions between the donor atoms and the coating surface/electrolyte interface or between the protonated thiourea species (such as $\mathrm{S}$ atom) on the surface [19]. Moreover, the presence of those heteroatoms such as N, P, and S in other heterocyclic compounds has been expected to enhance their adsorption onto IL due to their high electron density which facilitate an efficient transfer of electron on to the IL. Of all N-heterocycles compounds, 8-hydroxyquinoline (HQ), an outstanding complexing agent has been studied to protect metallic materials, such as $\mathrm{Mg}$ and $\mathrm{Al}$ alloys from corrosion attack by means of coordination complex (HQ-M, M:metal) formed between HQ and metal [21,22]. Immersion of porous IL into solution containing HQ for 1 day was anticipated to enhance corrosion behavior due to a formation of 3D branched-flower-like structure of OL on IL surface [11]. Figure 3a illustrates the formation mechanism of HQ-based HOI layer. The nucleation and growth of OL begin with the formation of primary crystal of charge transfer complex, where inorganic compounds in PE layer form a coordination complex with HQ molecules via physical and chemical coordination from $-\mathrm{OH}$ and $-\mathrm{C}=\mathrm{N}-$ (imine) groups, respectively. After primary cluster are formed in second stage, the growth of HQ layer originated at separate binding site in the porous PE layer causing individual petals to appear. In the last stage, the anisotropic growth of HQ aggregates and the complicated H-bonds between them lead to fine tuning of the whole system into a branched-lath shaped structure correspond to their concentration such as $0.05 \mathrm{M}$ and $0.1 \mathrm{M}$ HQ depicted in Figure 3b,c respectively [11]. As a continuation effort of this study, Al Zoubi and co-workers [12] introduced graphene oxide (GO) sheets having high chemical stability onto the flower-like structure of HQ to promote long term stability [12]. To this end, the IL was immersed in $1 \mathrm{M}$ HQ for 1 day at room temperature, forming OL with flower-like structures by means of the coordinated complex made between $\mathrm{O}$ and $\mathrm{N}$ atoms in $\mathrm{HQ}$ and $\mathrm{Mg}$ atoms in IL. GO are grown on the flower-like surface via physical adsorption ( $\pi-\pi$ interactions) between the aromatic structure in flower-like $\mathrm{HQ}$ and the benzene rings of graphite in GO, forming plate-like structure on the top of flower architecture as can be seen in Figure 3d [12].

In addition to $\mathrm{HQ}$, a synergy of two heterocyclic compounds was reported to promote the adsorption of organic molecules onto an inorganic surface by providing more electron donor sites [23]. In this work, imidazole with non-adjacent $\mathrm{N}$-atoms and 2-aminopyridine (AY) which contains a pyridine ring and an amino group were utilized. It is reported that not only physical adsorption arising from electrostatic interaction between negative charged molecule from organic compound and positive charged metal released from coating surface, forming charge transfer complex, but also chemical adsorption as a result from chelation of metal ions and AY molecule by means of delocalized $\pi$ electrons provided by $\mathrm{NH}_{2}$ having a highly electron-donating group [23].

More interestingly, a significant advance was made by Ko's group [24] on the fabrication of $\mathrm{HOI}$ layers on $\mathrm{Mg}$ alloys by introducing 2-mercaptobenzimidazole (MBI), a powerful organic corrosion inhibitor with a functional binding agents (FBAs) based on metal hydroxides [24]. The presence of a metal hydroxide as FBAs would make the available microdefects more uniform, providing more sites for local anchoring of MBI molecules, thereby facilitating the growth of OL on the IL surface [24,25].

In the first stage, the IL (Figure 4a) was immersed in ethanolic solution containing $\mathrm{Co}(\mathrm{OH})_{2}$ and $\mathrm{Mg}(\mathrm{OH})_{2}$ forming an infinite 2D sheet (Figure $\left.4 \mathrm{~b}\right)$. Subsequently, Co-Mg-IL was then immersed in $1 \mathrm{M}$ MBI for 1 day followed by air-drying at $373 \mathrm{~K}$ for $1 \mathrm{~h}$ to form carnation-shaped organic structures. 


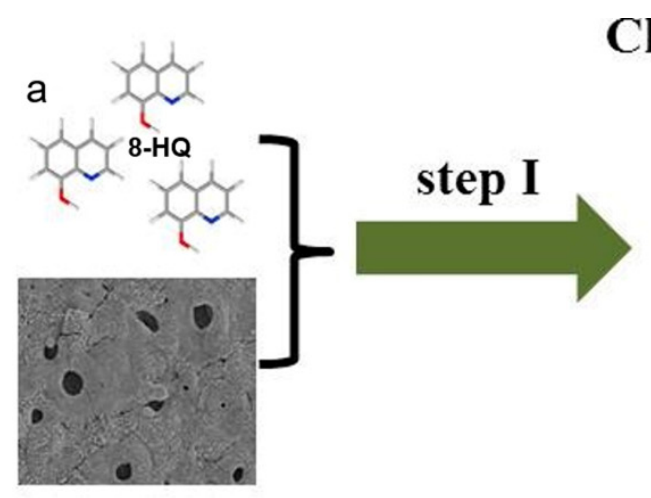

\section{Charge transfer complexes}
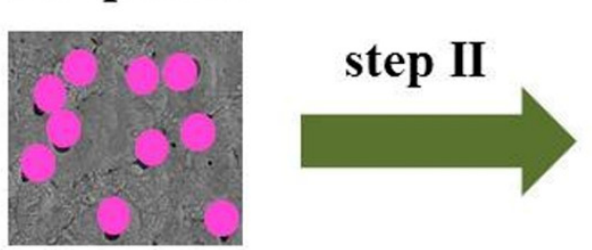

\section{Growth}

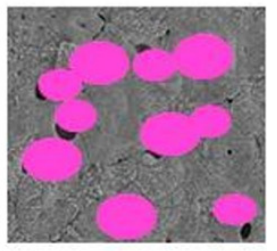

Aggregation
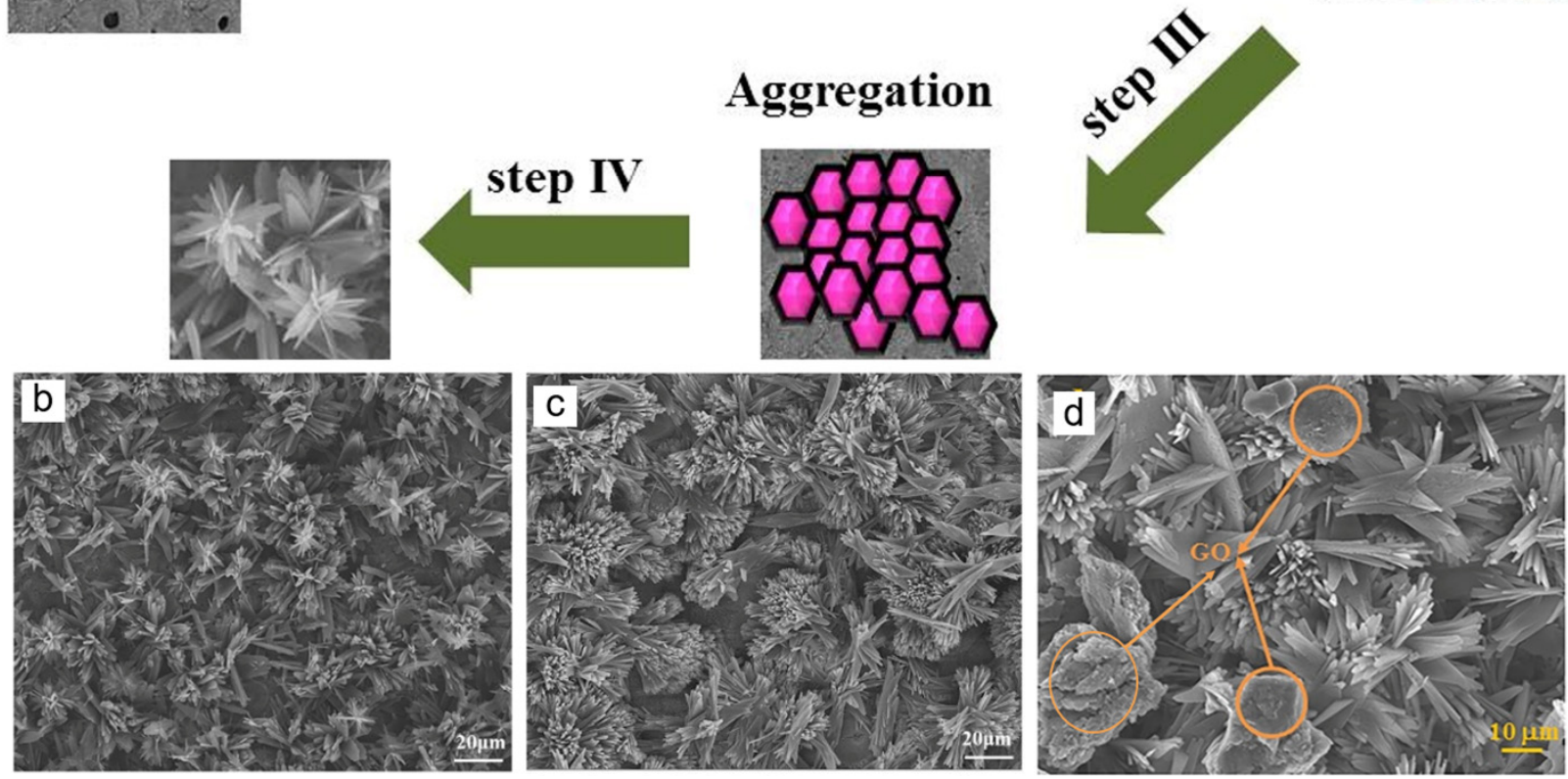

Figure 3. Schematic illustration (a) describing the synthetic mechanism of 8-HQ molecules self-assembled on IL-coated AZ31 Mg alloy for 1 days with different concentration of $0.05 \mathrm{M}(\mathbf{b}), 0.1 \mathrm{M}$ (c). Reproduced with permission [11]. Copyright (C) 2019 Elsevier. 1 M (d) with the additional GO layer. Reused with permission from [12]. Copyright (c) 2019 Elsevier.

At the first step of DCC, the electron donation from $\mathrm{Co}(\mathrm{OH})_{2}$ to $\mathrm{Mg}(\mathrm{OH})_{2}$ formed a double layer hydroxide, shown in Figure $4 \mathrm{~b}$, which provides preferential sites allowing the large MBI cluster agglomerates to grow on the remedied surface. The anisotropic growth of MBI- $\left[\mathrm{Co}(\mathrm{OH})_{2}-\mathrm{Mg}(\mathrm{OH})_{2}\right]$ lead to the formation of carnation-like structures as captured in Figure 4c [24]. The OL is formed on the IL as confirmed by HR-TEM shown in Figure 4d where the fringe with $0.23 \mathrm{~nm}$ inter-planar spacing is belong to $\left(\begin{array}{lll}1 & 0 & 1\end{array}\right)$ lattice plane of $\mathrm{Mg}(\mathrm{OH})_{2}$ and the inorganic particle surrounds the organic since the inter-planar spacing were measured to be 0.47 and $0.59 \mathrm{~nm}$ ascribed to $(002)$ and $(001)$ lattice planes of $\mathrm{Co}(\mathrm{OH})_{2}$ and $\mathrm{Co}(\mathrm{OH})\left(\mathrm{NO}_{3}\right)$. As shown in Figure 4e, MBI molecules in ethanolic solution can be adsorbed on the IL as thiol group (-SH) which is a primary core of chemisorption and in the form of anion as thione $(-\mathrm{N})$ or thiolate $(-\mathrm{NH})$ acted as secondary core which reacts with the FBAs-IL through $-\mathrm{N}-\mathrm{S}$ - bidentate ligand and hydrogen boding $(\mathrm{S}-\mathrm{H})$ to form a complex of IL-[Co(OH $\left.\left.)_{2}\right)-\mathrm{Mg}(\mathrm{OH})_{2}\right]-\mathrm{MBI}$ [24].

Based upon the recent investigations discussed above, it is interesting to note that the interactions between functional groups in organic compounds and metals in porous ILs modulated by covalent coordination might be more preferable than those facilitated by intermolecular forces such as Van der Waals and hydrogen bonding in satisfying the microstructural stability demands. As the structural integrity of the ILs is closely related to their electrochemical behavior, it is necessary to look into the protective performance of the various HOI system in the following section. 

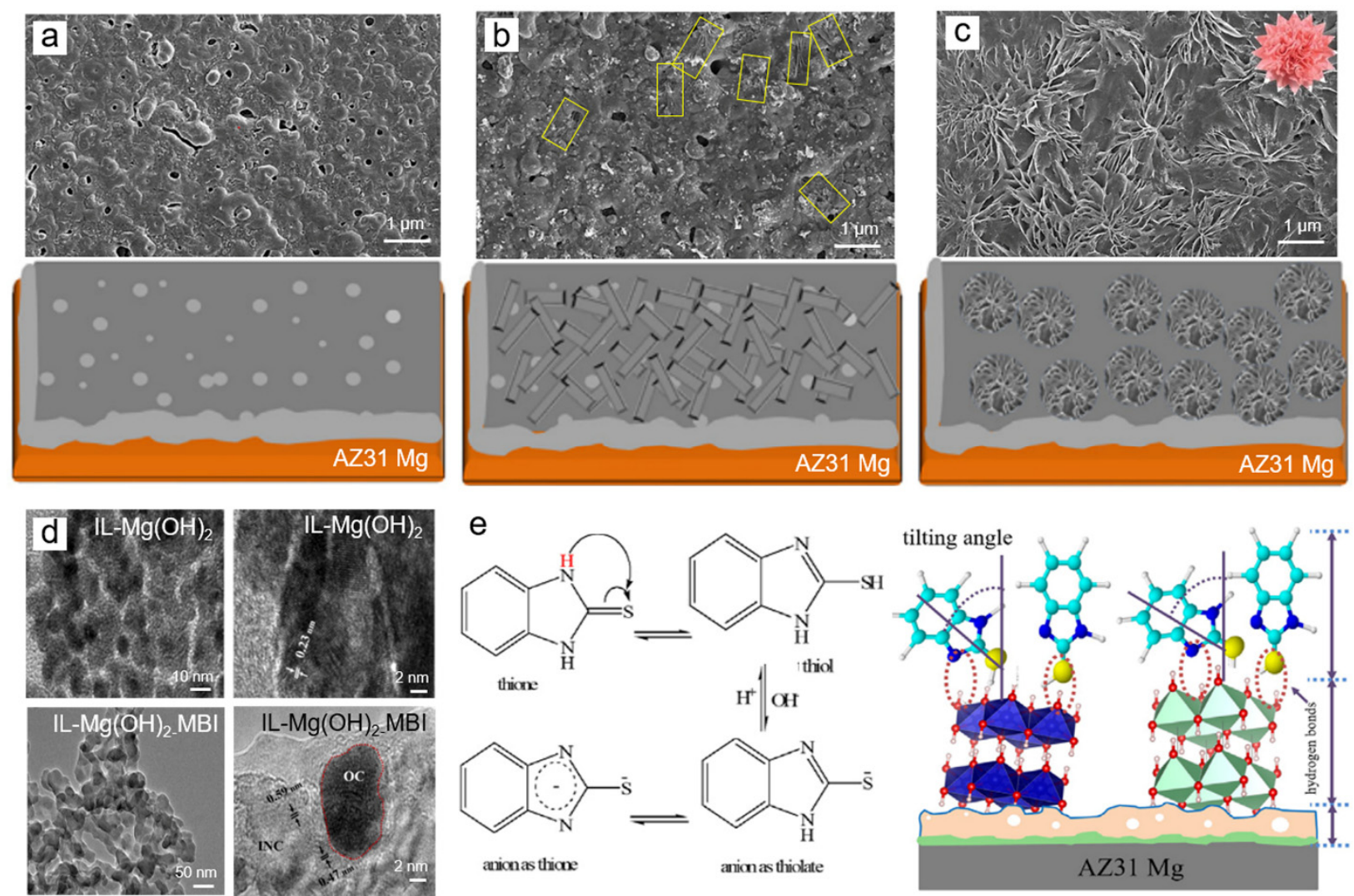

Figure 4. Structural changes in the surface of IL (a) fabricated on AZ31 Mg alloy by PE followed by first DCC in FBA containing solution resulting in IL-FBAs and (b) second DCC in ethanolic solution containing MBI at ambient temperature for one day to obtain IL-FBAs-MBI (c) Representative TEM and HR-TEM of IL-Mg(OH)2 and IL- $[\mathrm{Co}(\mathrm{OH}) 2)-\mathrm{Mg}(\mathrm{OH}) 2]-$ MBI (d), and Schematic illustration showing adsorption mechanism of MBI molecules on functionalized IL (e). Adapted with permission from [24]. Copyright $(2020$ Elsevier.

\section{Protective Performance: Polarization Behavior and Impedance Response}

In general, the deposition of HOI coatings on light metals and their alloys improves their electrochemical stability under extreme conditions due to the delayed attack of aggressive species on the metal surface leading to the enhancement of the anticorrosion behavior. Among electrochemical analyses, potentiodynamic polarization (PDP) and electrochemical impedance spectroscopy (EIS) are the most commonly used techniques to scrutinize the corrosion behavior of HOI coatings on metallic materials $[10,26,27]$. PDP technique is used to understand the corrosion rate and susceptibility of materials to corrosion, whilst EIS technique together with equivalent circuit modelling describes corrosion mechanism providing relevant information regarding the roles of coating layers $[19,28,29]$. Wang et al. [30] reported a hybrid coating which consisted of IL by PE self-assembled with polyethyleneimine (PEI) and Ag nanoparticles (AgNPs) by DCC. PEI as OL provides a good adhesion to the surface and effectively seals the substrate from corrosion due to the existence of amine groups [30]. The potentiodynamic polarization test results showed that the corrosion parameters, such as the value of $i_{\text {corr }}$, decreased from $6.97 \times 10^{-4} \mathrm{~A} \mathrm{~cm}^{-2}$ for bare $\mathrm{Mg}$ alloy to $2.90 \times 10^{-6} \mathrm{~A} \mathrm{~cm}^{-2}$ and $1.42 \times 10^{-7} \mathrm{~A} \mathrm{~cm}^{-2}$ for PE and PE/PEIAgNPs, respectively. Moreover, the values of polarization resistance were observed to be $1.33 \times 10^{5} \Omega \mathrm{cm}^{2}, 3.56 \times 10^{5} \Omega \mathrm{cm}^{2}$, and $8.71 \times 10^{6} \Omega \mathrm{cm}^{2}$ for bare $\mathrm{Mg}$ alloy, PE, and $\mathrm{PE} / \mathrm{PEI}-\mathrm{AgNPs}$, respectively, indicating that the defects on IL were preserved by synergistic effect of AgNPS and PEI layer [30].

Another similar approach was studied by Al Zoubi and co-workers [15] by using polyvinyl alcohol (PVA) via step-growth esterification-crosslinking reaction to provide strong bonding with $\mathrm{TiO}_{2}$ in IL in the presence of citric acid as crosslinking agent [15]. 
PVA-TiO $\mathrm{T}_{2} \mathrm{HOI}$ coating effectively hinders the penetration of aggressive ions into the Ti substrate which decreases the corrosion current density from $1.24 \times 10^{-6} \mathrm{~A} \mathrm{~cm}^{-2}$ to $1.5 \times 10^{-8} \mathrm{~A} \mathrm{~cm}^{-2}$ even after $12 \mathrm{~h}$ immersion in a corrosive medium. More interestingly, the corrosion resistance of the HOI coating improved, showing a larger capacitance loop than that of $\mathrm{TiO}_{2}$ after $90 \mathrm{~h}$ immersion, due to the self-sealing effect provided by PVA on the porous IL, suggesting that the hybrid coating exhibited excellent stability after a long immersion time [15].

In attempt to improve the anticorrosion performance of coatings on $\mathrm{Mg}$ alloy, Pak et al. [14] employed a combination of PE and DCC, that consisted of $\mathrm{MgO}$ and two chemical compounds, namely phytic acid (PA) and 3-aminopropyltrimethoxysilane (APTMS). Phytic acid is widely known to easily form a protective film on the surface of metals due to its capability of producing chelate compound with metal ions, while APTMS tends to form silane covalent bond [14]. By synergistic combination of PA and APTMS, the value of corrosion parameter, i.e $i_{\text {corr }}$ of $\mathrm{Mg}$ alloy decreased from $7.81 \times 10^{-5} \mathrm{~A} \mathrm{~cm}^{-2}$ to $3.90 \times 10^{-7} \mathrm{~A} \mathrm{~cm}^{-2}$ for $\mathrm{MgO}$ and $8.37 \times 10^{-8} \mathrm{~A} \mathrm{~cm}^{-2}$ for $\mathrm{MgO} / \mathrm{PA}-\mathrm{APTMS}$. Such reduction was associated with the formation of $\mathrm{Si}-\mathrm{OH}$ bond through hydrolysis of APTMS and interaction involving each PA molecules by means of dehydration-condensation reaction. Further investigation was made to study the corrosion behavior of $\mathrm{MgO} / \mathrm{PA}-\mathrm{APTMS}$ hybrid coatings which exhibited superior anti-corrosion performance to that $\mathrm{Mg}$ alloy in which the impedance value of $\mathrm{Mg}$ alloy, $\mathrm{MgO}$, and $\mathrm{MgO} / \mathrm{PA}-\mathrm{APTMS}$ are $6.90 \times 10^{2} \Omega \mathrm{cm}^{2}, 9.70 \times 10^{4} \Omega \mathrm{cm}^{2}$ and $5.02 \times 10^{5} \Omega \mathrm{cm}^{2}$, respectively. In particular, the circular pores generated by PE were sealed by the nanoscale structure of PA-APTMS during DCC [14]. Consequently, network structure of P-O-Si bonds interacted with $\mathrm{MgO}$ via $\mathrm{Mg}$-O-P bond, which provides highly stable covalent bonds.

Another study with similar concept combining IL by PE and OL comprising PA-Ce with the addition of silane-based coupling agent like $2 \mathrm{H}$-perfluorodecyltriethoxysilane (FAS) by DCC varying assembling cycles was reported by Jiang et al. [31]. The synergistic coordination among three components allows an increase in corrosion resistance of IL due to the formation of hydrophobic OL which was attributed to the presence of fluoro-alkyl group available in FAS molecule having high hydrophobicity in nature. Such hydrophobic characteristic is commonly determined by the value of contact angle, where the IL after three cycles of assembly (IL-(PA@Ce) 3 -FAS) shows an increase in contact angle value from $70^{\circ}$ to $159^{\circ}$, indicating better hydrophobic characteristic compared to the IL alone. This result was in line with the increase of its corrosion resistance, showed by a decrease in $i_{\text {corr }}$ value of IL-(PA@Ce) ${ }_{3}$-FAS by 1 order of magnitude from $8.2 \times 10^{-7} \mathrm{~A} \mathrm{~cm}^{-2}$. They suggested that the presence of Ce was considered to facilitate the chelation between PA and $\mathrm{Mg}^{2+}$ in IL to form coordination complex precipitated on the surface of IL. According to the Nyquist plots, capacitive loops of IL and IL-(PA@Ce) ${ }_{3}$-FAS after $72 \mathrm{~h}$ (Figure 5b) decreased compared to that evaluated for $1 \mathrm{~h}$ (Figure 5a). Nevertheless, the diameter of capacitance loop still sustains high value at low frequency, indicating that the corrosion of bare $\mathrm{Mg}$ alloy was likely to be suppressed by the hybrid coating [31]. To understand the corrosion mechanism, two different equivalent circuit models were then suggested to compare the corrosion behavior of IL and IL-(PA@Ce $)_{3}$-FAS displayed in Figure $5 \mathrm{c}-\mathrm{f}$ after immersion for $1 \mathrm{~h}$ and $72 \mathrm{~h}$ in $3.5 \mathrm{wt} . \% \mathrm{NaCl}$, respectively [31]. Even after $72 \mathrm{~h}$ immersion, IL-(PA@Ce) $3_{3}$ FAS maintained the value of constant phase element $(C P E)$ from $4.92 \times 10^{-7} \mathrm{~F} \mathrm{~cm}^{-2}$ to $5.05 \times 10^{-7} \mathrm{~F} \mathrm{~cm}^{-2}$ owing to a synergistic effect from the structure and composition of its super-hydrophobic HOI coating [31]. The covalent bonding between OH groups in PA and IL with low surface energy due to hydrolysis reaction of FAS would account for its superhydrophobic characteristics, while PA-Ce, an inherent corrosion inhibitor, plays a critical role responsible for preventing the substrate from further corrosion attack (Figure $5 \mathrm{~g}-\mathrm{i}$ ). 

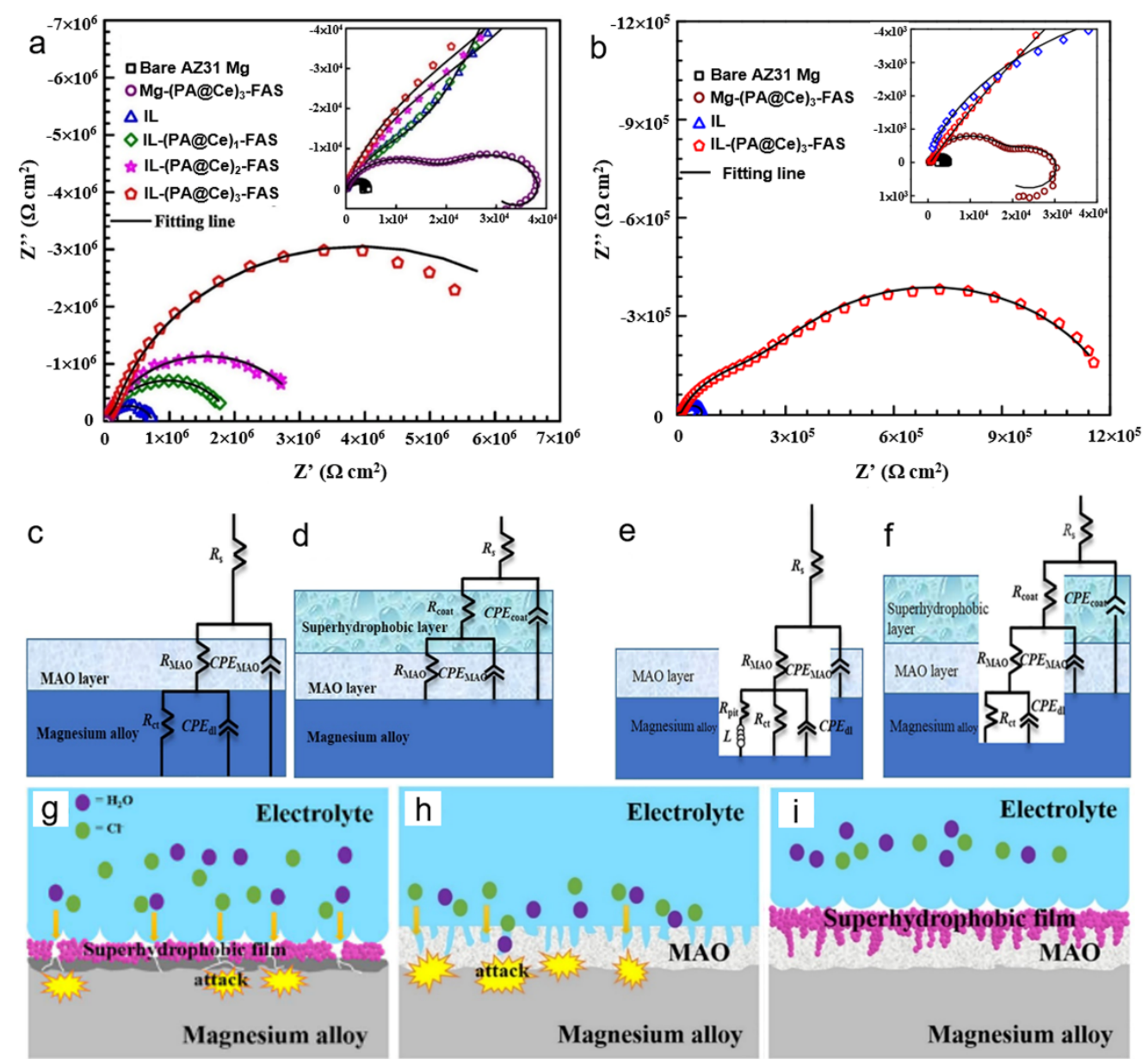

Figure 5. Impedance response showing Nyquist plot of IL-(PA@Ce)-FAS coatings and the bare Mg alloy after $1 \mathrm{~h}$ (a) and 72 $\mathrm{h}(\mathbf{b})$ immersion in $3.5 \mathrm{wt} \% \mathrm{NaCl}$. The proposed equivalent circuit models of IL and IL-(PA@Ce)-FAS after immersion for 1 $\mathrm{h}(\mathbf{c}, \mathbf{d})$ and $72 \mathrm{~h}(\mathbf{e}, \mathbf{f})$, respectively. A schematic illustration describing corrosion phenomena of metal-(PA@Ce)-FAS (g), IL (h), and IL-(PA@Ce)-FAS (i) was proposed. Reproduced with permission from [31]. Copyright @ 2018 Elsevier.

In addition to the previous works, a self-assembly of flower-like structures which resulted from the growth of 8-hydroxyquinoline-5-sulfonic acid (HQS) on porous IL was triggered by the interaction of conjugated double bonds within the aromatic rings and heteroatoms with IL. Al Zoubi et al. [32] fabricated a HOI material comprising IL-metalHQS (metal: $\mathrm{Na}$ and $\mathrm{Co}$ ) which contributed to the improvement of the electrochemical performance and chemical stability owing to both intermolecular locking of $\mathrm{H}$ atoms and interaction of $\pi-\pi$ bond within heterocyclic molecules with porous IL. The $i_{\text {corr }}$ values of IL-Na-HQS and IL-Co-HQS were measured to be $8 \times 10^{-8} \mathrm{~A} \mathrm{~cm}^{-2}$ and $6 \times 10^{-9} \mathrm{~A} \mathrm{~cm}^{-2}$, respectively, which were three and four orders of magnitude lower than that of bare $\mathrm{Mg}$ alloy as shown in Figure 6a. It is revealed that the anticorrosion behavior of HOI material relied strongly on the sealing effect of flower-like metal-HQS leading to a stable barrier against corrosive ions. In addition, the corrosion rate reduced from $4.0 \times 10^{-1} \mathrm{~mm} \mathrm{yr}^{-1}$ for $\mathrm{Mg}$ alloy to $2.8 \times 10^{-3} \mathrm{~mm} \mathrm{yr}^{-1}$ for IL-Co-HQS. After $70 \mathrm{~h}$ immersion, the capacitive loop of IL-Co-HQS presented in Figure $6 \mathrm{~b}, \mathrm{c}$ remained higher than that of $\mathrm{Mg}$ alloy which was ascribed to the stability of 3D flower-like structure due to the chemical bonding from complex coordination between metal-HQS and IL. A synergistic combination of IL and metal-HQS would maintained its flower architecture as depicted in Figure 6e, while the structural integrity of IL was deteriorated after $70 \mathrm{~h}$ immersion (Figure 6f) [32]. 

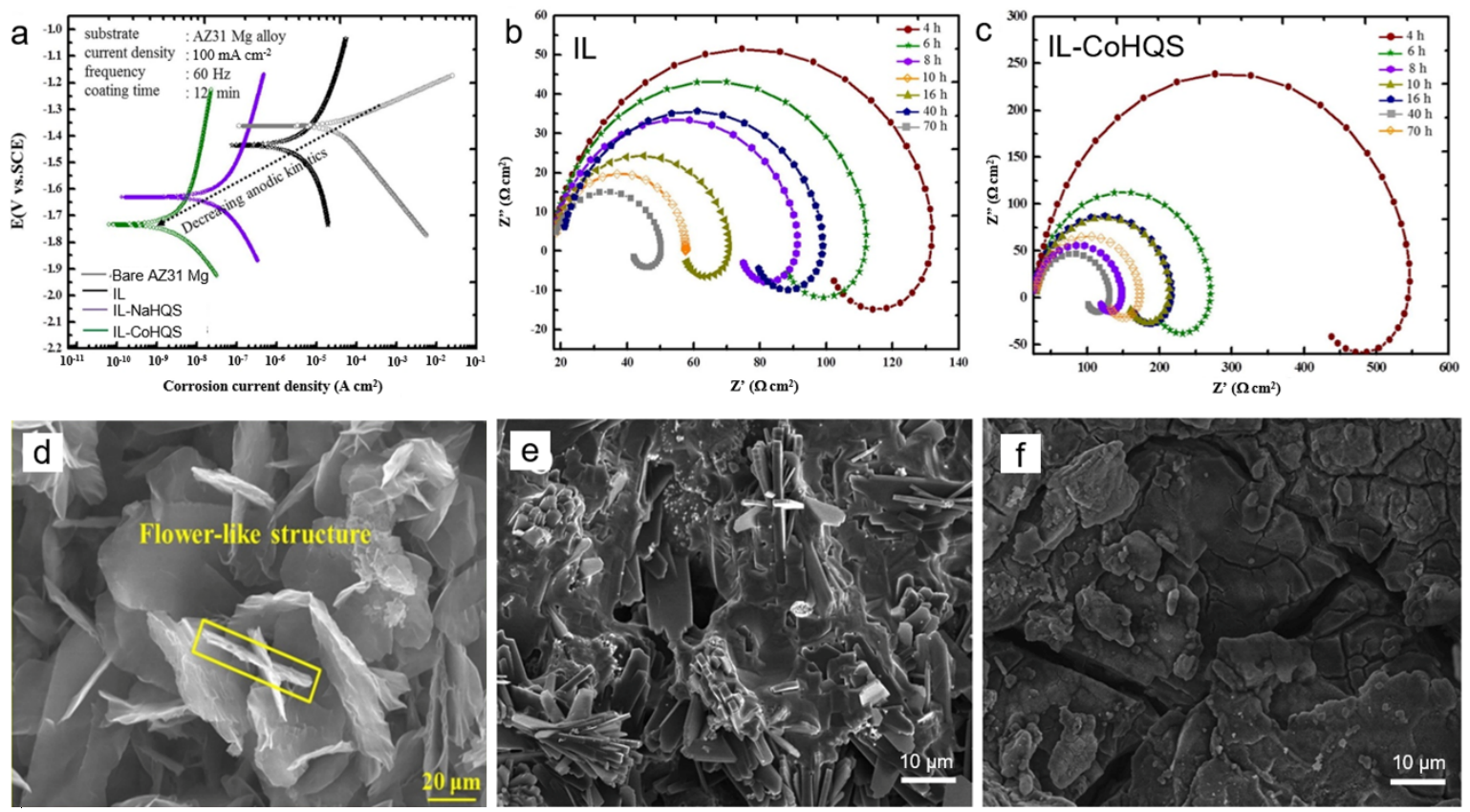

Figure 6. Electrochemical response showing (a) PDP curves of bare AZ31 Mg, IL, IL-NaHQS, IL-CoHQS after $1 \mathrm{~h}$ immersion and EIS curves of (b) IL and (c) IL-Co-HQS in $3.5 \mathrm{wt} . \% \mathrm{NaCl}$ at different immersion times. Surface morphology of IL-CoHQS before (d) and after corrosion test (e) in $3.5 \mathrm{wt}$.\% $\mathrm{NaCl}$ for $70 \mathrm{~h}$ showing structural stability as compared to that in IL (f) with identical immersion time. Redrawn with permission from [32]. Copyright () 2020 Elsevier.

To provide details regarding how the spatial architecture of HOI coatings would determine the electrochemical performance, we summarize a variety of hybrid organic and inorganic components fabricated on Mg alloy by two step PE and DCC in specific conditions followed by the evaluation of corrosion behavior of each material in Table 1 .

Table 1. Corrosion performance of $\mathrm{HOI}$ coating-based $\mathrm{Mg}$ alloy comprising various hybrid components in $3.5 \mathrm{wt} . \% \mathrm{NaCl}$.

\begin{tabular}{|c|c|c|c|c|c|c|c|}
\hline \multirow{3}{*}{ Substrate } & \multirow{3}{*}{$\begin{array}{l}\text { Hybrid Component } \\
\text { (IL/OL) }\end{array}$} & \multirow{3}{*}{$\begin{array}{l}\text { Concentration and } \\
\text { Immersion Time } \\
\text { During DCC }\end{array}$} & \multicolumn{4}{|c|}{ Corrosion Performance } & \multirow{3}{*}{ Ref. } \\
\hline & & & \multirow{2}{*}{$\begin{array}{c}i_{\text {corr }} \\
\left(\mathrm{A} \mathrm{cm}^{-2}\right)\end{array}$} & \multicolumn{2}{|c|}{$E_{\text {corr }}$} & \multirow{2}{*}{$\begin{array}{l}\text { Corrosion } \\
\text { Rate (mpy) }\end{array}$} & \\
\hline & & & & $\begin{array}{c}\text { (V vs. } \\
\text { Ag/AgCl) }\end{array}$ & (V vs. SCE) & & \\
\hline \multirow{11}{*}{ AZ31 Mg alloy } & \multirow{2}{*}{$\mathrm{MgO} / \mathrm{DMIP}$} & 1.0 M DMIP, $13 \mathrm{~h}$ & $4.95 \times 10^{-7}$ & -0.39 & \multirow{5}{*}{-} & \multirow[t]{2}{*}{-} & \multirow{2}{*}[10]{} \\
\hline & & $1.0 \mathrm{M}$ DMIP, $30 \mathrm{~h}$ & $2.01 \times 10^{-9}$ & -0.24 & & & \\
\hline & $\mathrm{Mg}(\mathrm{OH})_{2} / \mathrm{MBI}$ & $1.0 \mathrm{M} \mathrm{MBI}, 24 \mathrm{~h}$ & $2.54 \times 10^{-8}$ & -1.05 & & $1.16 \times 10^{-1}$ & \multirow{2}{*}{ [25] } \\
\hline & $\begin{array}{c}\mathrm{Mg}(\mathrm{OH})_{2}-\left[\mathrm{Co}(\mathrm{OH})_{2-}\right. \\
\mathrm{Mg}(\mathrm{OH})_{2}^{-} \\
\left.\mathrm{Co}(\mathrm{OH})\left(\mathrm{NO}_{3}\right)\right] / \mathrm{MBI}\end{array}$ & $\begin{array}{c}1.0 \mathrm{M} \mathrm{KOH} \text { or } 1.0 \mathrm{M} \\
\mathrm{Co}\left(\mathrm{NO}_{3}\right)_{2} \cdot 6 \mathrm{H}_{2} \mathrm{O}, 1.0 \mathrm{M} \\
\mathrm{MBI}, 24 \mathrm{~h}\end{array}$ & $1.00 \times 10^{-8}$ & -0.73 & & $4.60 \times 10^{-3}$ & \\
\hline & $\mathrm{MgAl}_{2} \mathrm{O}_{4} / \mathrm{H}_{2} \mathrm{NCSNH}_{2}$ & $0.2 \mathrm{M} \mathrm{H}_{2} \mathrm{NCSNH}_{2}, 20 \mathrm{~h}$ & $8.00 \times 10^{-8}$ & \multirow[t]{3}{*}{-1.63} & & \multirow{7}{*}{-} & [19] \\
\hline & $\mathrm{MgAl}_{2} \mathrm{O}_{4} / \mathrm{DEIP}$ & 1.0 M DEIP, $24 \mathrm{~h}$ & $1.17 \times 10^{-9}$ & & -0.31 & & [20] \\
\hline & $\mathrm{MgAl}_{2} \mathrm{O}_{4}-\mathrm{TiO}_{2} / \mathrm{DEIP}$ & $\begin{array}{c}1.0 \mathrm{M} \text { DEIP, } 0.06 \mathrm{M} \mathrm{TiO}_{2} \\
48 \mathrm{~h}\end{array}$ & $2.61 \times 10^{-10}$ & & 0.17 & & \\
\hline & \multirow{2}{*}{$\mathrm{MgAl}_{2} \mathrm{O}_{4} / \mathrm{PPC}$} & $1.0 \mathrm{M} \mathrm{PPC}, 24 \mathrm{~h}$ & $4.80 \times 10^{-8}$ & -0.23 & & & \multirow{2}{*}{ [13] } \\
\hline & & $2.0 \mathrm{M} \mathrm{PPC}, 24 \mathrm{~h}$ & $1.60 \times 10^{-8}$ & -0.11 & & & \\
\hline & $\mathrm{MgO} / \mathrm{PA}-\mathrm{APTMS}$ & $0.09 \mathrm{M}$ PA-APTMS, $1.5 \mathrm{~h}$ & $8.37 \times 10^{-8}$ & \multirow[t]{2}{*}{-} & -1.37 & & {$[14]$} \\
\hline & 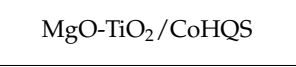 & $\begin{array}{c}0.02 \mathrm{M} \mathrm{Co}\left(\mathrm{NO}_{3}\right)_{2} \cdot 6 \mathrm{H}_{2} \mathrm{O} \\
0.06 \mathrm{M} \mathrm{HQS}\end{array}$ & $6.00 \times 10^{-9}$ & & -1.73 & & [32] \\
\hline AM50B Mg alloy & $\mathrm{MgO} / \mathrm{MTES}$ & 2 wt. $\%$ MTES, 3 h & $1.45 \times 10^{-7}$ & & -1.52 & $5.73 \times 10^{-3}$ & [9] \\
\hline AZ91 Mg alloy & $\mathrm{MgO} / \mathrm{PA}-\mathrm{Ce}\left(\mathrm{NO}_{3}\right)_{3} / \mathrm{FAS}$ & $\begin{array}{c}0.01 \mathrm{M} \mathrm{PA}, 0.01 \mathrm{M} \\
\mathrm{Ce}\left(\mathrm{NO}_{3}\right)_{3} \\
1 \text { wt. } \% \text { FAS, } 2 \mathrm{~h}\end{array}$ & $3.50 \times 10^{-8}$ & & -1.36 & - & [31] \\
\hline
\end{tabular}

DEIP: diethyl-5-hydroxyisophthalate, DMIP: dimethyl-5-hydroxyisophthalate, MBI: 2- mercaptobenzimidazole, PPC: 4-[4(phyenylazo)phenylazo]-o-cresol, PA: phytic acid, APTMS: 3-aminopropyltrimethyoxysilane, HQS: 8-hydroxyquinoline-5-sulfonic acid, MTES: methyltriethoxysilane, FAS: 2H-perfluorodecyltriethoxysilane. 


\section{Conclusions}

In this review, we have outlined and discussed recent reports on the formation mechanism of HOI materials on light metals using PEO and DCC. The wide choice of organic components may govern a broad variation of HOI materials satisfying the demand for desired structural features. The interactions between organic molecules and the porous inorganic layer occurred through charge-transfer-type interactions and electrostatic interactions between the electron atom donor and the inorganic components in the coating surface. Electrochemical performances of HOI materials measured by using potentiodynamic polarization and EIS Bode plots tests in aggressive solution were reviewed together with corrosion protection and corrosion mechanism. The authors believe that the HOI materials lead to superior corrosion protection of because synergistic combination of individual components (i.e., organic and inorganic compounds) in enhancing structure compactness and chemical stabilities.

Author Contributions: N.N. and R.A.K.P. have an equal contribution in literature review and writing the original draft, E.Z.A. constructed figures and table, W.A.Z. contributed in conceptualization, reviewing and editing, Y.G.K. contributed in supervision and funding acquisition. All authors have read and agreed to the published version of the manuscript.

Funding: This work was supported by the Mid-Level Researcher National Project of the National Research Foundation (NRF) funded by the Ministry of Science and ICT, Republic of Korea (NRF2020R1A2C2004192).

Institutional Review Board Statement: Not applicable.

Informed Consent Statement: Not applicable.

Data Availability Statement: Not applicable.

Conflicts of Interest: The authors declare no conflict of interest.

\section{References}

1. Al Zoubi, W.; Kamil, M.P.; Fatimah, S.; Nisa, N.; Ko, Y.G. Recent advances in hybrid organic-inorganic materials with spatial architecture for state-of-the-art applications. Prog. Mater. Sci. 2020, 112, 100663. [CrossRef]

2. Francis, A.; Yang, Y.; Boccaccini, A.R. A new strategy for developing chitosan conversion coating on magnesium substrates for orthopedic implants. Appl. Surf. Sci. 2019, 466, 854-862. [CrossRef]

3. Al Zoubi, W.; Ko, Y.G. Chemical stability of synergistic inorganic materials for enhancing electrochemical performance. Compos. Sci. Technol. 2020, 199, 108383. [CrossRef]

4. Nashrah, N.; Kamil, M.P.; Yoon, D.K.; Kim, Y.G.; Ko, Y.G. Formation mechanism of oxide layer on AZ31 Mg alloy subjected to micro- arc oxidation considering surface roughness. Appl. Surf. Sci. 2019, 497, 143772. [CrossRef]

5. Casanova, L.; La Padula, M.; Pedeferri, M.P.; Diamanti, M.V.; Ormellese, M. An insight into the evolution of corrosion resistant coatings on titanium during bipolar plasma electrolytic oxidation in sulfuric acid. Electrochim. Acta 2021, 379, 138190. [CrossRef]

6. Becerikli, M.; Kopp, A.; Kroger, N.; Bodrova, M.; Wallner, C.; Wagner, J.M.; Dadras, M.; Jettkant, B.; Pohl, F.; Lehnhardt, M.; et al. A novel titanium implant surface modification by plasma electrolytic oxidation (PEO) preventing tendon adhesion. Mater. Sci. Eng. C 2021, 123, 112030. [CrossRef]

7. Attarzadeh, N.; Molaei, M.; Babaei, K.; Fattah-alhosseini, A. New Promising Ceramic Coatings for Corrosion and Wear Protection of Steels: A Review. Surf. Interfaces 2021, 23, 100997. [CrossRef]

8. Lu, X.; Blawert, C.; Huang, Y.; Ovri, H.; Zheludkevich, M.L.; Kainer, K.U. Plasma electrolytic oxidation coatings on Mg alloy with addition of SiO2 particles. Electrochim. Acta 2016, 187, 20-33. [CrossRef]

9. Malayoglu, U.; Tekin, K.C.; Shrestha, S. Influence of post-treatment on the corrosion resistance of PEO coated AM50B and AM60B Mg alloys. Surf. Coat. Technol. 2010, 205, 1793-1798. [CrossRef]

10. Al Zoubi, W.; Kamil, M.P.; Yang, H.W.; Ko, Y.G. Self-assembly of basket-weave organic layer formed on defective inorganic surface. Chem. Eng. J. 2019, 360, 385-392. [CrossRef]

11. Al Zoubi, W.; Ko, Y.G. Self-assembly of hierarchical N-heterocycles-inorganic materials into three-dimensional structure for superior corrosion protection. Chem. Eng. J. 2019, 356, 850-856. [CrossRef]

12. Al Zoubi, W.; Kim, M.J.; Kim, Y.G.; Ko, Y.G. Fabrication of graphene oxide/8-hydroxyquinolin/inorganic coating on the magnesium surface for extraordinary corrosion protection. Prog. Org. Coat. 2019, 137, 105314. [CrossRef]

13. Al Zoubi, W.; Ko, Y.G. Flower-like Organic-Inorganic Coating Responsible for Extraordinary Corrosion Resistance via Selfassembly of an Organic Compound. ACS Sustain. Chem. Eng. 2018, 6, 3546-3555. [CrossRef] 
14. Pak, S.; Jiang, Z.; Yao, Z.; Ju, J.; Ju, K.; Pak, U. Fabrication of environmentally friendly anti-corrosive composite coatings on AZ31B $\mathrm{Mg}$ alloy by plasma electrolytic oxidation and phytic acid / 3-aminopropyltrimethoxysilane post treatment. Surf. Coat. Technol. 2017, 325, 579-587. [CrossRef]

15. Al Zoubi, W.; Kim, M.J.; Kim, Y.G.; Ko, Y.G. Dual-functional crosslinked polymer-inorganic materials for robust electrochemical performance and antibacterial activity. Chem. Eng. J. 2020, 392, 123654. [CrossRef]

16. Tsai, D.-S.; Chou, C.-C. Review of the Soft Sparking Issues in Plasma Electrolytic Oxidation. Metals 2018, 8, 105. [CrossRef]

17. Kamil, M.P.; Kaseem, M.; Ko, Y.G. Soft plasma electrolysis with complex ions for optimizing electrochemical performance. Sci. Rep. 2017, 7, 1-15. [CrossRef]

18. Kamil, M.P.; Al Zoubi, W.; Yoon, D.K.; Yang, H.W.; Ko, Y.G. Surface modulation of inorganic layer via soft plasma electrolysis for optimizing chemical stability and catalytic activity. Chem. Eng. J. 2020, 391, 123614. [CrossRef]

19. Al Zoubi, W.; Ko, Y.G. Enhanced Corrosion Protection Performance by Organic-Inorganic Materials Containing Thiocarbonyl Compounds. Sci. Rep. 2018, 8, 1-11. [CrossRef]

20. Al Zoubi, W.; Min, J.H.; Ko, Y.G. Hybrid organic-inorganic coatings via electron transfer behaviour. Sci. Rep. 2017, 7, 1-15. [CrossRef]

21. Lamaka, S.; ML, Z.; KA, Y.; MF, M.; MGS, F. High effective organic corrosion inhibitors for 2024 aluminium alloy. Electrochim. Acta 2007, 52, 7231-7247. [CrossRef]

22. Gao, H.; Li, Q.; Dai, Y.; Luo, F.; Zhang, H.X. High efficiency corrosion inhibitor 8-hydroxyquinoline and its synergistic effect with sodium dodecylbenzenesulphonate on AZ91D magnesium alloy. Corros. Sci. 2010, 52, 1603-1609. [CrossRef]

23. Al Zoubi, W.; Yoon, D.K.; Ko, Y.G. Fabrication of heterocycles-inorganic materials for enhancing corrosion resistance. J. Mol. Liq. 2020, 308, 113160. [CrossRef]

24. Al Zoubi, W.; Yoon, D.K.; Kim, Y.G.; Ko, Y.G. Fabrication of organic-inorganic hybrid materials on metal surface for optimizing electrochemical performance. J. Colloid Interface Sci. 2020, 573, 31-44. [CrossRef] [PubMed]

25. Al Zoubi, W.; Ko, Y.G. A novel strategy to modify the surface of plasma electrolysis produced inorganic coatings for fabricating organic@functional binding agents@inorganic materials. J. Alloy. Compd. 2019, 776, 1025-1028. [CrossRef]

26. Kaseem, M.; Fatimah, S.; Nashrah, N.; Ko, Y.G. Recent progress in surface modification of metals coated by plasma electrolytic oxidation: Principle, structure, and performance. Prog. Mater. Sci. 2020, 100735. [CrossRef]

27. Martin, J.; Haraux, P.; Ntomprougkidis, V.; Migot, S.; Bruyère, S.; Henrion, G. Characterization of metal oxide micro/nanoparticles elaborated by plasma electrolytic oxidation of aluminium and zirconium alloys. Surf. Coat. Technol. 2020, 397, 125987. [CrossRef]

28. Hakimizad, A.; Raeissi, K.; Golozar, M.A.; Lu, X.; Blawert, C.; Zheludkevich, M.L. Influence of cathodic duty cycle on the properties of tungsten containing Al2O3/TiO2 PEO nano-composite coatings. Surf. Coat. Technol. 2018, 340, 210-221. [CrossRef]

29. Gawel, L.; Nieuzyla, L.; Nawrat, G.; Darowicki, K.; Slepski, P. Impedance monitoring of corrosion degradation of plasma electrolytic oxidation coatings (PEO) on magnesium alloy. J. Alloy. Compd. 2017, 722, 406-413. [CrossRef]

30. Wang, X.; Yan, H.; Hang, R.; Shi, H.; Wang, L.; Ma, J.; Liu, X.; Yao, X. Enhanced anticorrosive and antibacterial performances of silver nanoparticles/polyethyleneimine/MAO composite coating on magnesium alloys. J. Mater. Res. Technol. 2021, 11, 2354-2364. [CrossRef]

31. Jiang, D.; Zhou, H.; Wan, S.; Cai, G.Y.; Dong, Z.H. Fabrication of superhydrophobic coating on magnesium alloy with improved corrosion resistance by combining micro-arc oxidation and cyclic assembly. Surf. Coat. Technol. 2018, 339, 155-166. [CrossRef]

32. Al Zoubi, W.; Ko, Y.G. Freestanding anticorrosion hybrid materials based on coordination interaction between metal-quinoline compounds and TiO2-MgO film. J. Colloid Interface Sci. 2020, 565, 86-95. [CrossRef] [PubMed] 